\title{
Synthesis of Gold Nanorods for Application in Photothermal Therapy
}

Jorge Iriqui $^{1}$, Pedro-A. Hernandez-A. ${ }^{1,2}$, Hiram Higuera-V. ${ }^{1}$, Nadia. Garcia-F. ${ }^{2}$, Eleazar León ${ }^{1}$ and M.E. Álvarez-Ramos ${ }^{2}$

${ }^{1}$ Universidad Estatal de Sonora, Hermosillo, Sonora, Mexico, ${ }^{3}$ Universidad de Sonora, Hermosillo, Sonora, Mexico

In this work, gold nanorods were prepared and characterized for his potential application in phototermic therapy. Localized thermotherapy photo meets the foundation of traditional thermotherapy with the difference that photothermal heating only occurs in the area directly around certain nanoparticles such as gold nanorods, these nanosystems are capable of generating heat by being irradiated by a laser in the near infrarred range of the electromagnetic spectrum, ensuring that local temperatures can rise to tens of degrees above the physiological temperature. The use of nanostructures implies that photothermal heating can be more directed at tumors, potentially reducing the negative side effects of cancer therapies.

Synthesis of these gold nanorods was performed following the seed-mediated method. The seed solution was prepared mixing $10 \mathrm{ml}$ of $200 \mathrm{mM} \mathrm{CTAB}\left(\mathrm{C}_{19} \mathrm{H}_{42} \mathrm{BrN}\right)$ solution with $10 \mathrm{ml}$ of $0.5 \mathrm{mM} \mathrm{HAuCl} 4$. Next, a solution $10 \mathrm{mM}$ of $\mathrm{NaBH}_{4}$ was added to the gold seed solution. A growth solution was prepared by pouring $10 \mathrm{ml}$ of $200 \mathrm{mM} \mathrm{CTAB}$ solution into $0.30 \mathrm{ml}$ of $4 \mathrm{mM} \mathrm{AgNO} 3$ solution at room temperature. Then $10 \mathrm{ml}$ of $1 \mathrm{mM}$ of $\mathrm{HAuCl}_{4}$ was poured into this solution, and after gentle mixing, $0.14 \mathrm{ml}$ of $80 \mathrm{mM}$ ascorbic acid ( $\left.\mathrm{C}_{6} \mathrm{H} 8 \mathrm{O} 6\right)$ was added. Finally, $0.024 \mathrm{ml}$ of the seed solution was added to the growth solution at room temperature and left for $1 \mathrm{~h}$ to react. (1)

Scanning electron microscopy was performed with a JEOL JSM-7800F. Figure 1 shows the microscopy of a sample. The presence of rods approximately $50 \mathrm{~nm}$ long can be observed, with high homogeneity in size. A clear separation between rods is observed, indicating the absence of agglomeration.

The heating tests were carried out by irradiating the samples with an $808 \mathrm{~nm}$ diode laser (Changchun New Industries Optoelectronics Tech Co. LTD, Model No. PSU-111-LED), which was placed at a distance of $1.8 \mathrm{~m}$ from the sample at different powers $(1 \mathrm{~W}, 1.5 \mathrm{~W}$ and $2 \mathrm{~W}$.) and with a thermometer the temperature change in the solution was measured. Figure 2 show the graph of temperature vs time difference of gold nano rods irradiated at different laser powers at a wavelength of $808 \mathrm{~nm}$, where we can see that the greater the intensity the greater the difference in temperature produced. 


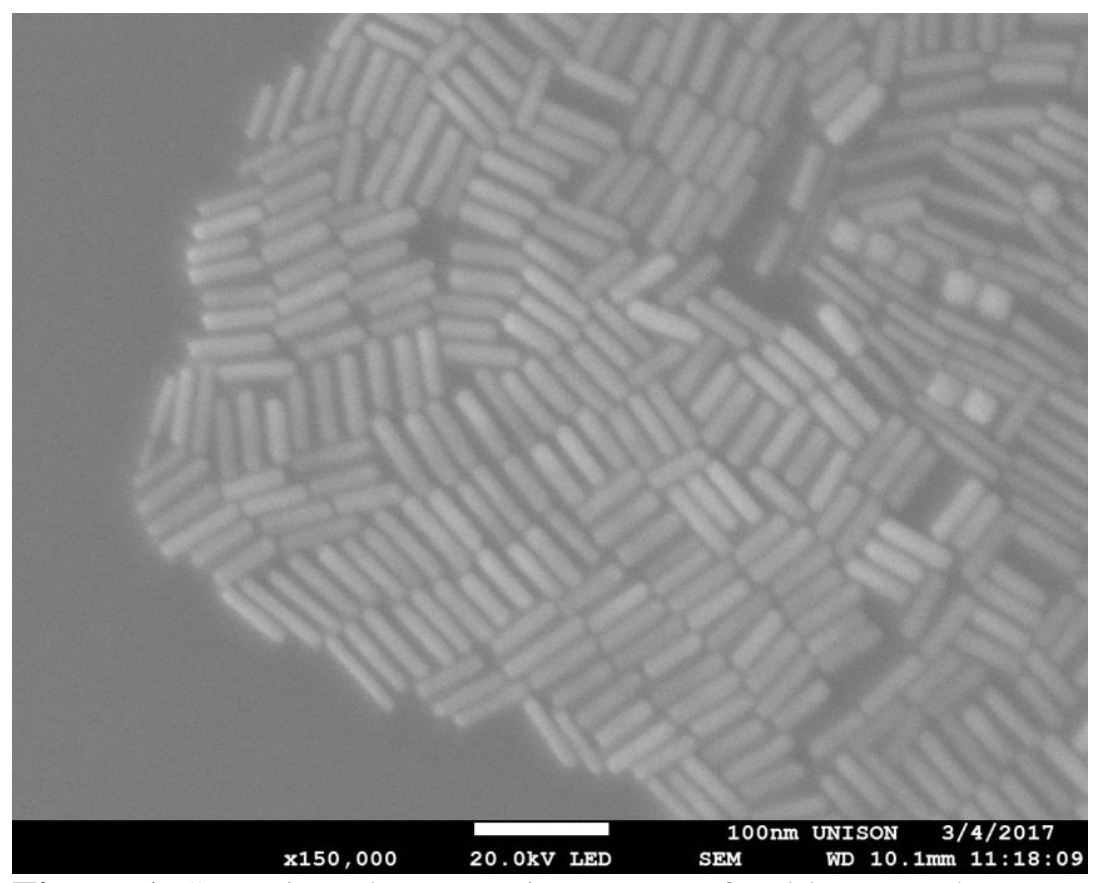

Figure 1. Scanning electron microscopy of gold nanorods

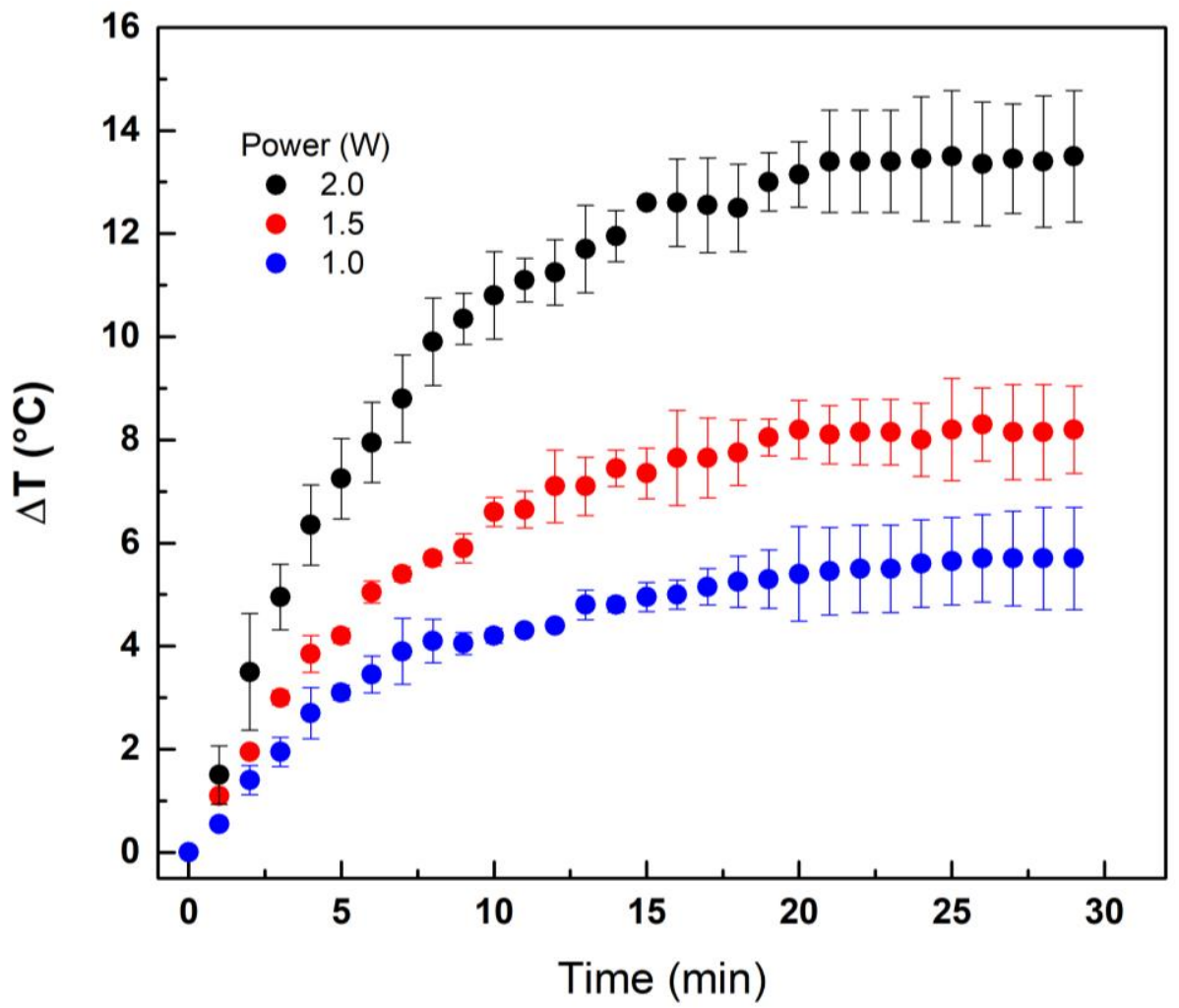

Figure 2. Heating tests for gold nanorods samples, irradiated with an $808 \mathrm{~nm}$ diode laser.

\section{References}

1. Esquivel, R., Canale, I., Ramirez, M., et al. (2017). Poly(N-isopropylacrylamide)-coated gold nanorods mediated by thiolated chitosan layer: thermo-pH responsiveness and optical properties. e-Polymers, 18(2), pp. 163-174. 